\title{
CARACTERÍSTICAS DO TRABALHO NA AGRICULTURA FAMILIAR E SUA INFLUÊNCIA NA EMIGRAÇÃO DOS JOVENS
}

\author{
Michele Barth ${ }^{1}$ \\ Jacinta Sidegum Renner ${ }^{2}$ \\ Margarete Fagundes Nunes ${ }^{3}$ \\ Gustavo Roese Sanfelice ${ }^{4}$
}

\section{Introdução ${ }^{5}$}

O tempo dedicado ao trabalho ocupa uma parcela substancial na vida das pessoas. Segundo Marx (1993), trabalho é, genericamente, a capacidade de transformar a natureza para suprir as necessidades humanas. Codo (1997: 26) define o trabalho como "uma relação de dupla transformação entre o homem e a natureza, geradora de significado". O significado do trabalho faz referência às representações que o sujeito tem de sua atividade e o valor que lhe atribui (Morin, 1996; Tolfo; Piccinini, 2007).

O trabalho desenvolvido na agricultura familiar ${ }^{6}$ é de suma importância para a economia, assim como, para toda população. De acordo com o Ministério do Desenvolvimento Agrário, este segmento produz cerca de $70 \%$ dos alimentos consumidos diariamente pelos brasileiros, ocupando quase $75 \%$ da mão de obra do campo (Brasil, 2012). Apesar dos avanços tecnológicos, principalmente para as grandes lavouras agrícolas, ainda há inúmeros empreendimentos de agricultura de pequeno e médio porte, geralmente desenvolvidos pelos membros da família. Segundo o Censo Agropecuário $^{7}$ de $2006,9,4 \%$ da área territorial brasileira é ocupada por

\footnotetext{
${ }^{1}$ Universidade Feevale, Brasil.

${ }^{2}$ Universidade Feevale, Brasil.

${ }^{3}$ Universidade Feevale, Brasil.

${ }^{4}$ Universidade Feevale, Brasil.

${ }^{5}$ A presente pesquisa é oriunda de Trabalho de Conclusão de Curso que foi desenvolvida no ano de 2014, sob a orientação da Dra. Jacinta S. Renner. Em 2015, em virtude da inserção no Programa de Pósgraduação em Diversidade Cultural e Inclusão Social, o artigo incorpora outras leituras ao escopo teórico. ${ }^{6} \mathrm{Na}$ agricultura familiar ocorre a produção de alimentos através do trabalho realizado pelos membros de uma família, geralmente caracterizada pela policultura em lotes de 5-50 hectares, mesclando atividades de subsistência, produção comercial e, não tão significativa, integração agroindustrial (Wilkinson, 2000; Brumer, 2004).

${ }^{7}$ De acordo com o Instituto Brasileiro de Geografia e Estatística (2006), o Censo Agropecuário investiga os estabelecimentos agropecuários e as atividades neles desenvolvidas, obtendo informações detalhadas sobre as características do produtor e do estabelecimento, bem como sobre a economia e o emprego no meio rural, no que diz respeito à agricultura, pecuária e agroindústria.
} 
estabelecimentos da agricultura familiar, empregando $6,5 \%$ da população nesse setor (IBGE, 2006). Corroborando com estes dados, Mesquita e Mendes (2012) afirmam que a agricultura familiar é responsável pela geração de empregos no ambiente rural, além de contribuir com a segurança alimentar, com a questão ambiental, econômica e social.

No Rio Grande do Sul (RS), 22\% da área territorial são ocupados por estabelecimentos da agricultura familiar, empregando 9,3\% da população gaúcha (IBGE, 2006). Com exceção da região campeira, as demais áreas apresentam relevo montanhoso dificultando o cultivo dos alimentos com máquinas agrícolas. Além disso, os alimentos produzidos na agricultura familiar são, em sua maioria, frutas, verduras e legumes, os quais são volumosos e/ou frágeis, impossibilitando o cultivo e a colheita com máquinas. Deste modo os produtores rurais acabam utilizando ferramentas rudimentares e maior mão de obra braçal nas atividades.

O pequeno agricultor, além de realizar grande esforço físico devido à tecnologia restrita, ainda está sujeito a inúmeros acidentes de trabalho, aos efeitos nocivos dos raios de sol, às temperaturas extremas do clima da região sul e ao risco de ser atacado por animais peçonhentos. Devido a estas características do trabalho na agricultura familiar, é possível perceber que este público está submetido a condições de trabalho muitas vezes insalubres e críticas em termos ergonômicos ${ }^{8}$. Estas condições são dependentes da variedade e quantidade de produtos cultivados, pois acaba sendo necessária a dedicação do produtor quase em tempo integral para a realização do trabalho, incluindo os finais de semana. Além disso, os trabalhadores dificilmente gozam de um período de férias durante o ano, o que potencializa ainda mais a sobrecarga de trabalho.

As precárias condições de trabalho da agricultura familiar tem sido um dos principais motivos que tem levado muitos agricultores a abandonarem esta atividade e optarem pelo trabalho em indústria. Segundo as pesquisas de Camarano e Abramovay (1999), a partir da década de 1960 tem aumentado a taxa de migração do meio rural para o meio urbano. Os autores destacam que, por volta de 1990, a maioria das migrações era de jovens entre 15 e 19 anos de idade, principalmente do sexo feminino. Sob o ponto de vista da modernização do espaço agrário brasileiro, Mesquita e Mendes (2012: 14) alegam que as recentes transformações ocorridas afetaram "as pequenas e

\footnotetext{
${ }^{8}$ A Ergonomia é uma disciplina científica que procura entender as interações entre os seres humanos e outros elementos ou sistemas, onde são aplicadas teorias, princípios, dados e métodos a projetos para otimizar o bem estar humano e o desempenho global do sistema (Abergo, 2014).
} 
médias propriedades rurais, provocando a descapitalização e a exclusão social do pequeno agricultor, o que trouxe como consequência o êxodo rural". Rocha e Eckert (2015) comentam que os processos migratórios para as cidades polos de trabalho e emprego foram acentuadas pela desvalorização do trabalho rural na pequena e média propriedade, fazendo surgir o setor de serviços e funções.

Neste contexto, percebe-se o dispendioso tempo dedicado ao trabalho na agricultura familiar e o certo desprezo dos jovens às características das atividades nesse setor. Essas questões se correlacionam com a qualidade de vida no trabalho (QVT). Conforme Schuch (2001), a QVT tem por finalidade humanizar as relações de trabalho, mantendo relação com a produtividade e a satisfação do trabalhador em seu ambiente de trabalho. O autor acrescenta que a QVT está relacionada à condição de vida no trabalho, ao bem estar, à saúde e a segurança do trabalho. Walton (1973) afirma que a QVT depende de oito fatores: compensação justa e adequada; condições de segurança e saúde no trabalho; utilização e desenvolvimento de capacidades; oportunidades de crescimento e segurança; integração social na organização; garantias constitucionais; trabalho e espaço total de vida; e relevância social da vida no trabalho.

Diante deste cenário, apresenta-se o seguinte problema de pesquisa: qual o significado do trabalho para os trabalhadores da agricultura familiar e como as condições de trabalho podem interferir na migração dos jovens para as cidades? Propôsse como objetivo geral investigar a percepção dos agricultores a respeito do seu trabalho e analisar os motivos que levaram os jovens, filhos de agricultores, a buscar outros empregos. Os objetivos específicos estiveram focados em verificar a percepção dos agricultores sobre seu trabalho; averiguar o índice de sucessão dos filhos no empreendimento da família; e investigar, com os pais agricultores, o motivo dos filhos não permanecerem no empreendimento familiar.

\section{Materiais e métodos}

Esta pesquisa se caracteriza como observacional descritiva, que objetiva conhecer e interpretar, classificar, explicar, registrar e descrever os fatos que ocorrem (Moraes; Mont'alvão, 2012; Prodanov; Freitas, 2009). A análise e discussão de dados foi realizada sob o paradigma qualitativo. Segundo Víctora et al. (2000), o método qualitativo procura entender o contexto em que algum fenômeno ocorre, permitindo a 
observação de vários elementos em um pequeno grupo. A perspectiva interdisciplinar da pesquisa buscou o diálogo com as ciências sociais, em especial a antropologia, que foi fundamental para ir além da coleta das narrativas desses trabalhadores, e buscar incorporar informações relevantes oriundas da observação-participante e imagens desse cotidiano, a partir da fotografia. Segundo Eckert e Rocha (2008), a observação participante consiste na participação do pesquisador-observador das rotinas do grupo social estudado, objetivando maior aprofundamento da pesquisa. $\mathrm{O}$ uso da fotografia teve a intenção de refletir sobre a relação corpo, saúde e trabalho. Mendonça, Barbosa e Durão (2007) afirmam que a fotografia, quando usada com enfoque metodológico, tem a capacidade de conter informações de maneira mais confiável e econômica, o que permite uma catalogação mais eficiente dos dados pesquisados.

O campo de estudo foi o município de Linha Nova, localizada na região serrana no interior do Rio Grande do Sul, cuja economia está voltada principalmente para a agricultura familiar, no cultivo de hortifrutigranjeiros. As entrevistas foram realizadas através do contato direto com os trabalhadores, por meio de visita às residências das famílias de agricultores que produzem verduras e legumes.

Em termos de procedimentos de pesquisa, observa-se que uma das pesquisadoras é moradora da cidade que é campo deste estudo, o que facilitou a adesão e participação dos trabalhadores. A pesquisadora iniciou as entrevistas com as famílias de agricultores mais próximos, mais conhecidas da sua família. A partir disso, deu-se início a um processo natural de envolvimento de outras famílias que espontaneamente se pronunciaram querendo participar da pesquisa. A proposta inicial era de entrevistar no máximo 20 famílias, o que foi ampliado para 34 famílias.

Antes do início das entrevistas, foi realizada uma breve explicação do objetivo da pesquisa, do método utilizado, a relevância da participação dos entrevistados e o retorno dos resultados que seria dado aos entrevistados em momento oportuno. $\mathrm{O}$ instrumento de pesquisa foi constituído de uma entrevista semi-estruturada, compostas de questões abertas que tiveram por objetivo identificar o perfil dos sujeitos da pesquisa, compreender sua percepção em relação à centralidade do trabalho, as características do trabalho e o sentido deste na sua vida e na vida da família. Outro aspecto que foi questionado nas entrevistas com os pais, teve relação com a quantidade de filhos que permanecem atuando na agricultura familiar, além de questionar o motivo da emigração destes para as cidades. 
A análise e discussão dos dados ocorreu pelo método de triangulação. Segundo os estudos de Marcondes e Brisola (2014), neste método de análise é realizado um modus operandi pautado na preparação do material coletado e na articulação de três aspectos para proceder à análise: os dados empíricos levantados na pesquisa; o diálogo com os autores que estudam a temática em questão; e a análise de conjuntura. Segundo Souza e Zioni (2003: 78) o método de triangulação permite "uma maior validade dos dados e uma inserção mais aprofundada dos pesquisadores no contexto de onde emergem os fatos, as falas e as ações dos sujeitos".

Por fim, vale salientar que ocorreu reunião no dia 7 de julho de 2015, para retorno da pesquisa à comunidade. Levando em consideração que todos os anos ocorre a Assembleia Geral Ordinária da Associação de Desenvolvimento Agrícola de Linha Nova (ADA), aproveitou-se este momento para apresentar os resultados da pesquisa para o público envolvido.

\section{Resultados}

Os resultados serão apresentados em três subtítulos: características do perfil dos agricultores englobando sexo, idade, escolaridade, tempo de atuação na agricultura familiar, número de filhos e quantidade de filhos que migraram para as cidades em busca de outros empregos. O segundo enfoque da análise e discussão gira em torno dos três polos apontados por Ribas (2003), ou seja, a visão dos agricultores sobre estes aspectos do trabalho na agricultura (negativo, neutro e positivo). Por fim, o último aspecto discutido tem relação com o significado e qualidade de vida no trabalho e discute a visão dos pais sobre a migração dos filhos para as grandes cidades.

\section{Características do perfil dos agricultores}

O grupo de estudo foi constituído por 34 famílias. Estas somaram o total de 80 entrevistados, todos atuantes na agricultura. Destes, 47 são do sexo masculino e 33 do sexo feminino. A idade média dos agricultores que compuseram o grupo pesquisado é de 45 anos, sendo que o entrevistado mais jovem tinha 15 anos e o mais velho 76 anos de idade. A média de tempo de atuação nas atividades da agricultura é de 30 anos. O 
tempo médio da jornada de trabalho é de 9 h diárias. A média do grau de escolaridade é $5^{\mathrm{a}}$ série do ensino fundamental.

Com relação ao número de filhos, obteve-se a média de 1,75 , ou seja, quase dois filhos por família. Quanto ao número de jovens na agricultura, os resultados indicaram que das 34 famílias entrevistadas, 29 tiveram filhos. Totalizaram-se 63 filhos, onde 11 são menores de 15 anos. Dos demais, 18 permanecem trabalhando na agricultura familiar - 15 do sexo masculino e apenas 3 do sexo feminino. Há diferentes fatores que influenciam na decisão dos jovens na permanência ou não no empreendimento agrícola da família, dentre eles estão as características do trabalho agrícola, as facilidades de acesso à educação, ao transporte, às tecnologias, aproximação das indústrias, entre outros, os quais serão explanados no decorrer deste artigo.

\section{Polos de representação do trabalho}

Ao questionar os entrevistados se gostam do trabalho na agricultura, as respostas indicaram grande diversidade de opiniões, embora a maioria entenda que o trabalho na agricultura é importante, alguns se referem a ele apenas como uma necessidade. Neste sentido, dada a diversidade de opiniões, podemos discuti-las sob a ótica de Ribas (2003) que evidencia a partir das suas pesquisas três posições de representação do trabalho, denominadas como polo negativo, centro contínuo e polo positivo.

Conforme Ribas (2003), o trabalho não se constitui somente de valor econômico, mas também de valor cultural e de autoestima. O autor comenta que, antigamente, a visão do trabalho oscilava entre o centro contínuo bipolar e o polo negativo. Contudo, na modernidade industrial, as mudanças nas formas de trabalho e emprego trazem implicações objetivas e subjetivas, envolvendo tanto as condições socioeconômicas, como o significado, o sentido e o valor sociocultural dessa experiência. Assim, segundo o autor, esta perspectiva do trabalho se inverte, se estendendo do centro contínuo até o polo positivo. 
No que tange ao polo negativo do trabalho, Ribas (2003) afirma que este acaba sendo considerado como maldição, castigo, jugo, estigma, coerção, esforço e penalidade. Isso foi exposto por alguns trabalhadores da seguinte forma:

\begin{abstract}
Trabalho mais por obrigação, não por gosto. Porque quando a coisa aperta tu trabalha de tudo. [...] O bom é que não tem patrão, onde eu mesmo faço minhas horas e eu sou o meu patrão. Posso relaxar um pouco de vez em quando, mas não tem quem faça o serviço por mim. [...] Deveríamos ter mais auxílio do governo. Só se trabalha com financiamento. Na agricultura não se tem garantia nenhuma. Não se tem o dinheiro fixo no final do mês. $\mathrm{O}$ retorno que temos precisa ser reaplicado na agricultura. $\mathrm{O}$ pessoal da cidade recebe um salário $\mathrm{X}$ e pode aproveitar dele. Eu preciso trabalhar para sobreviver. (Agricultor de 45 anos de idade)
\end{abstract}

A gente se obriga. É o jeito da gente sobreviver. A gente não tem estudo e o que fazer? Trabalhar na roça [...] Mas o trabalho tá bem melhor, mais fácil de trabalhar, porque hoje em dia tem máquinas. Antigamente tinha que lavrar tudo a boi. [...] $\mathrm{O}$ problema são os preços das coisas, tem que trabalhar muito para ganhar dinheiro. Sol quente e quando tá tudo molhado também é muito ruim. (Agricultor de 50 anos de idade).

Essas expressões nos reportam a pensar e refletir sobre a percepção do trabalho como uma condição de "castigo" imposto pela necessidade de sobrevivência. Tolfo e Piccinini (2007) comentam que, quando o trabalho é reconhecido como algo obrigatório e necessário para a sobrevivência e aquisições, o homem deixa de reconhecê-lo como categoria integradora, deixando de buscar sua identidade nas atividades que executa.

Numa das falas é reportado sobre o baixo grau de escolaridade como fator negativo, que restringe as oportunidades de trabalho em outros ambientes. Schwartzman e Cossio (2015) observaram que, principalmente jovens sem o ensino médio completo, apresentam rendimentos muito mais baixos e maior nível de desemprego que aqueles com o ensino médio concluído.

Além disso, trazem em evidência pontos negativos como o trabalho sobre o sol e a chuva, o baixo valor dos alimentos para comercialização e a falta de uma renda fixa mensal. Salienta-se que a renda destes agricultores depende significativamente das oscilações dos preços dos alimentos nas Centrais de Abastecimento. Ainda é relevante citar as condições climáticas, presença de predadores e a qualidade das sementes e insumos adquiridos para o bom desenvolvimento dos alimentos. Um dos entrevistados comenta que, apesar de não ter um rendimento fixo mensal por ser autônomo, necessita reinvestir o capital adquirido em seu negócio. 
Apesar de reconhecerem negativamente o trabalho na agricultura, mencionam pontos positivos como a liberdade do trabalho e os avanços tecnológicos. No entanto, observa-se que apesar dos avanços tecnológicos, poucas mudanças ocorreram no modo de executar as tarefas na pequena agricultura. O trabalho ainda é pesaroso e exige sobrecarga física, posturas estáticas prolongadas, levantamento e carregamento de cargas manuais e trabalho manual repetitivo (Monteiro, 2004). Pessoa e Alchiere (2014) expõem que a agricultura familiar ficou à margem do progresso tecnológico, o qual foi encaminhado às grandes propriedades agrícolas. Essa realidade de trabalho é visível nas imagens que seguem.

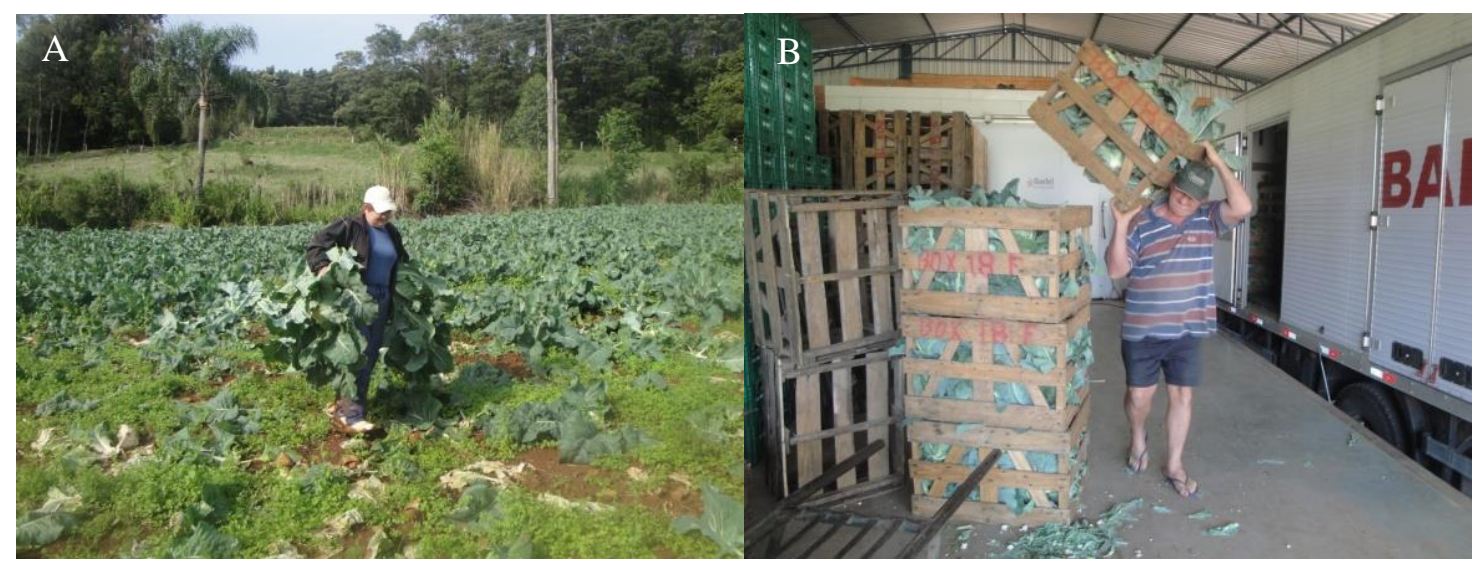

Figura 1: Características artesanais da colheita da couve-flor na agricultura familiar. (A) Agricultora carregando a couve-flor para fora da plantação; (B) Agricultor descarregando caixas de madeira com couve-flor do caminhão. Fonte: Autores (2014).

Nas Figuras 1A e 1B observam-se características artesanais do trabalho, sendo que ainda persiste o manuseio de cargas associado ao esforço físico. Estes aspectos são típicos da agricultura de pequeno porte, onde o maquinário e a automatização ainda são incipientes.

Kroemer e Grandjean (2005) alegam que a coluna sofre mais com o manuseio da carga do que os músculos. De acordo com Renner (2005), o peso do material transportado tende a sobrecarregar as estruturas musculoesqueléticas e os discos intervertebrais, que, ao longo do tempo, resultará no desgaste das estruturas ósseas, articulares e dos discos intervertebrais. Em relação à musculatura, as forças aplicadas no manuseio de cargas elevadas aliada às posturas inadequadas e repetições exageradas dos 
movimentos, podem ocasionar dores como resultado de alongamento excessivo e/ou inflamação dos músculos, tendões e articulações (Iida, 2005).

Ao tentar estabelecer correlações entre o motivo da migração dos jovens da agricultura familiar para novas oportunidades de emprego nas cidades maiores e industrializadas, na opinião da maioria das famílias entrevistadas, um dos fatores que influencia na busca por outros empregos é a própria característica da atividade agrícola. Alguns entrevistados justificaram a escolha dos filhos da seguinte maneira: "Pois não querem se judiar. Querem um trabalho mais fácil." (Agricultor de 64 anos de idade, pai de dois filhos). Outros informaram que os filhos jamais manifestaram interesse pelas atividades agrícolas: "Porque não se interessam e tentaram outras carreiras. Elas estudaram e receberam emprego na cidade e nunca gostaram de ir na roça." (Agricultora de 43 anos de idade, mãe de cinco filhos).

Essa realidade de trabalho pesado também se configura nas Figuras $2 \mathrm{~A}$ e 2B, onde se encontra posturas em flexão de coluna com sobrecarga física, o que tende a provocar dor/desconforto durante e/ou ao final da jornada de trabalho. A presença ou não da dor depende de uma série de fatores tais como: desempenho físico para o trabalho pesado (se prática exercício físico), o tempo de exposição ao risco (tempo em que permanece em flexão de tronco) e ainda as intempéries do tempo (se frio ou calor).

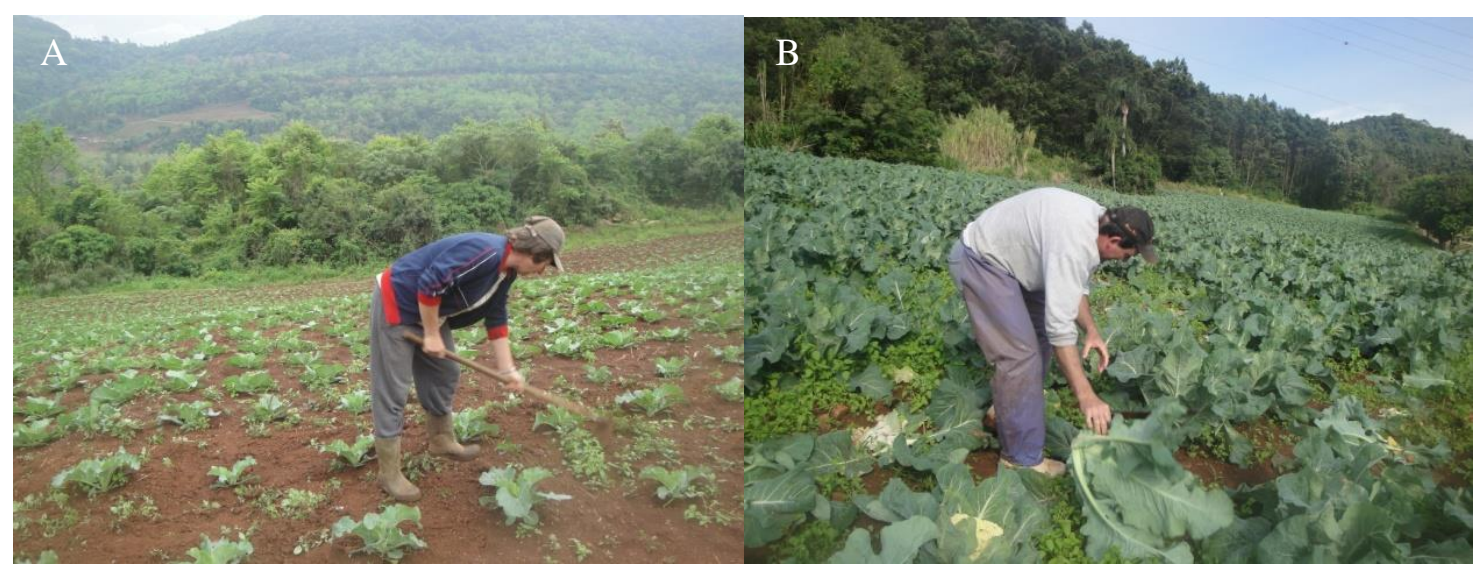

Figura 2: Posturas críticas de flexão e rotação de coluna vertebral durante o cultivo e colheita da couveflor. (A) Agricultora retirando ervas daninhas da plantação de couve-flor com auxílio de enxada; (B) Agricultor realizando o corte da couve-flor. Fonte: Autores (2014). 
As situações de posturas críticas evidenciadas na Figura 2 são muito comuns. Neste caso em especial, o que mais se configura é a postura em flexão associada à rotação de coluna vertebral e ainda, ao emprego de força quer seja pelo manuseio da enxada (Figura 2A) e ou, pelo ato de realizar o corte e a retirada da couve flor da plantação (Figura 2B). Estas posturas acabam implicando em risco para desgastes osteoarticulares e patologias degenerativas da coluna vertebral, assim como, são fatores coadjuvantes na formação de hérnias de disco (protusão e degeneração do disco intervertebral).

Iida (2005: 557) afirma que "a colheita de produtos agrícolas geralmente exige posturas incômodas e a própria mão é usada como 'ferramenta'". Dul e Weerdmeerter (2012) explicam que posturas e movimentos inadequados produzem tensões mecânicas nos músculos, ligamentos e articulações, ocasionando dores em diversas partes do sistema musculoesquelético. Gomes Filho (2010) chama atenção para a postura incorreta adotada a longo prazo, podendo causar fadiga muscular e constrangimentos físicos como a deformação da coluna vertebral, tendinites, entre outros graves problemas.

Observa-se que estes elementos associados formam um conjunto de fatores que, aos olhos de quem faz este trabalho, se torna pesaroso, difícil e exaustivo. Isso foi expresso pelos pais da seguinte forma: “os filhos não querem mais se judiar que nem nós, preferem um trabalho menos forçado" (agricultor de 64 anos de idade, pai de dois filhos) e ainda, "o trabalho na roça é muito judiado, quem estudou não quer isso, prefere algo mais fácil" (agricultora de 49 anos de idade, mãe de três filhos).

Seguindo os pressupostos de Ribas (2003), a segunda categoria proposta pelo autor tem relação com o trabalho quando é visto e percebido como neutro, ou centro contínuo. Segundo o autor, ocupa mera função instrumental para sobrevivência material, realizando a dedicação necessária somente para o alcance deste objetivo. Em algumas respostas percebe-se principalmente o desinteresse para a aquisição de experiências em outros locais de trabalho, preferindo a permanência nas atividades agrícolas. Nesse sentido, houve respostas como:

Porque cada um tem que trabalhar na vida para se sustentar. Só as vezes o tempo não colabora. [...] Mas hoje em dia tá melhor, pois tem mais máquinas; a prefeitura ajuda mais os agricultores. Só que tem que produzir mais. Pouca coisa não adianta mais. Os preços dos produtos tão mais altos, mas os adubos e os venenos também aumentaram. Quando os preços tão muito caros, o pessoal das cidades também não compra. [...] O clima é diferente de anos atrás. Tá tudo misturado. No inverno não é 
mais tão frio, isso influencia no couve-flor. [...] As vezes tu trabalha só pra se sustentar e as vezes dá dinheiro. (Agricultor de 36 anos de idade)

Só se trabalhou nisso. Nunca se pensou em outro lugar para trabalhar. A gente não tem tanta escolaridade [...] O trabalho na agricultura já melhorou bastante por causa dos implementos. Antigamente só tinha os bois. Com bois não se faz mais produção. (Agricultor de 51 anos de idade)

Sempre fiz isso. Desde pequena trabalhamos nisso. [...] O trabalho podia ser melhor, podia ser mais leve. [...] Seria bom se não precisasse trabalhar no frio e na chuva. [...] É ruim tem que trabalhar em sábados e domingos. Não temos final de semana. (Agricultora de 51 anos de idade)

Apesar de trazerem pontos positivos como o avanço tecnológico e as políticas de incentivo à agricultura, resta-nos tentar compreender se este "desinteresse" tem sua origem no receio de aprender algo novo em função da baixa escolaridade, o que tende a minimizar as oportunidades de emprego, ou se ocorre um processo de acomodação naquela condição de trabalho que lhes é familiar, conhecida e dominada em termos de modus operandi.

Ainda, nos polos neutro e negativo é importante salientar a falta de significado que o trabalho pode ter para quem o executa. Tolfo e Piccinini (2007) destacam o sofrimento causado pela significação do trabalho, o que pode comprometer a saúde mental. Para que haja uma vida dotada de sentido, é necessário que o indivíduo encontre na esfera do trabalho o primeiro momento de realização. Se o trabalho for autodeterminado, autônomo e livre, será também dotado de sentido ao possibilitar o uso autônomo do tempo livre que o ser social necessita para se humanizar e se emancipar em seu sentido mais profundo (Tolfo; Piccinini, 2007).

Nas falas acima, nota-se que, são enfatizados como pontos negativos, novamente as frequentes alterações climáticas prejudiciais para o desenvolvimento dos produtos, o alto valor agregado aos insumos e mantimentos agrícolas, as características do trabalho pesado e a dedicação quase integral ao trabalho.

Com relação ao polo positivo mencionado por Ribas (2003), as características de um trabalho com significado foram apontadas de forma predominante na opinião dos trabalhadores, no entanto, observa-se que neste caso em especial, predomina a opinião dos pais e não dos jovens. $\mathrm{O}$ autor descreve o trabalho desta categoria como missão, vocação, caminho, valor, fonte de satisfação e de auto-realização. Apesar de ser reconhecido como judiado, é dada ênfase à liberdade e à autonomia proporcionada pelo trabalho como empreendimento familiar. 
Tendo em vista a liberdade conferida pelo trabalho na agricultura familiar, as falas referem-se tanto à liberdade no trabalho, quanto à satisfação de trabalhar próximo à natureza e ao ar livre, tendo sido expresso da seguinte forma: "Gosto, porque o serviço é mais livre. Não precisa se incomodar com patrões.” (Agricultor de 49 anos de idade);

É judiado, mas tu trabalha como tu quer e como tu pode. [...] Antigamente se nós não trabalhava, o pai nos apanhava. A metade do dinheiro que ganhávamos fora, ainda tinha que dar pros pais. (Agricultora de 42 anos de idade)

Porque é um serviço que gosto de fazer. Dá mais liberdade. Dá bom retorno. Não precisa se incomodar com ninguém. [...] Hoje tá melhor, pois temos trator. Se fosse como antigamente íamos morrer de fome, não teria como sobreviver. [...] Um problema é que a gasolina sobe e o preço dos produtos continua baixo. Que nem o preço do milho... tá baixo e é difícil a venda. (Agricultor de 42 anos de idade)

Tu fica mais à vontade. Trabalha quando tu quer. Não precisa cumprir horário. [...] $\mathrm{O}$ pessoal que planta verduras poderia ganhar um pouco mais. [...] O clima é um problema. Chove e tu não consegue trabalhar. Apodrece tudo quando chove demais. [...] O trabalho agora tá bom. Recém compramos equipamentos para trator e ficou melhor. (Agricultor de 53 anos de idade)

Sou uma pessoa que não gosto de trabalhar em ambiente fechado. Gosto de variar de um trabalho para o outro, de um serviço para o outro. [...] Hoje o trabalho tá excelente. A tecnologia está tornando o serviço cada vez mais fácil. A tendência é que o mercado cresça cada vez mais, pois alimento todo mundo precisa. [...] Poderia existir mais maquinário para facilitar o trabalho. Melhorar as sementes para que produzissem mais em menos espaço. Poder usar menos agrotóxicos... (Agricultora de 37 anos de idade)

Neste caso, as respostas indicam que a autonomia proporcionada pelo trabalho agrícola, que não tem imposição de carga horária e nem é exercido em um parque fabril com controles rígidos de processo, acaba sendo preponderante na escolha por este trabalho. Na maioria das indústrias ainda predomina o sistema taylorista/fordista, que impõe uma condição de trabalho repetitiva, monótona e de pouco significado. $\mathrm{O}$ principal objetivo do sistema taylorista/fordista era o alcance da produtividade máxima. Lima e Holzmann (2015) comentam que o taylorismo implicou no crescimento da estrutura hierárquica das empresas, multiplicando-se os cargos de chefia e supervisão. Segundo Matos e Pires (2006: 509), este sistema trouxe como efeitos negativos "a fragmentação do trabalho com separação entre concepção e execução, que associada ao controle gerencial do processo e à hierarquia rígida tem levando a desmotivação e alienação de trabalhadores, bem como a desequilíbrios nas cargas de trabalho". 
Com relação ao conteúdo e significado do trabalho, Morin (2001: 16) expõe que a "maneira como os indivíduos trabalham e o que eles produzem têm um impacto sobre o que pensam e na maneira como percebem sua liberdade e sua independência". Um trabalho que permita o indivíduo desenvolver sua autonomia e perceber seu senso de responsabilidades também faz com que este mantenha o interesse pelo trabalho (Morin, 2001).

O fato de que o indivíduo tem que resolver problemas durante a realização do trabalho e exercer seu julgamento para tomar decisões relativas à organização das suas atividades reforça o sentimento de competência e eficácia pessoal; isso tem uma influência direta não somente no desenvolvimento da autonomia pessoal mas também na motivação. Além disso, o fato de ter que resolver problemas e vencer dificuldades estimula a criatividade dos indivíduos. (Morin, 2001: 16)

Nas falas ainda é feito menção à melhora do trabalho devido aos investimentos em maquinários agrícolas. Contudo, um dos entrevistados comenta que poderiam haver mais máquinas para auxiliar as atividades da agricultura familiar o que evidencia a escassez de novos implementos neste setor. E uma das entrevistadas expõem as condições de trabalho na sua infância, onde estes eram obrigados a trabalhar na agricultura junto à família e, quando recebiam uma renda fora do trabalho familiar deveria ser dividida com os pais.

Ainda, em relação ao polo positivo, alguns entrevistados mencionaram a satisfação de trabalhar ao ar livre, na terra e com produtos naturais: "Porque é um lugar que se trabalha ao ar livre; não tá sempre na mesma função; não enjoa." (Agricultor de 20 anos de idade); "Por ser ao ar livre, ar puro. [...] O problema é esse clima, temos muita perda por causa do excesso de frio ou calor." (Agricultora de 37 anos de idade); "Porque é interessante mexer com a terra. [...] Melhoraria poder usar mais ferramentas para ajudar no trabalho." (Agricultora de 15 anos de idade);

Porque é diferente. Poder ver o desenvolvimento das plantas, estar sempre junto... [...] Para alguns o trabalho é muito precário e para outros muito avançado. Alguns se dão bem com a tecnologia, outros não. [...] Seria bom se as coisas (produtos naturais) não demorassem tanto para estarem prontos. (Agricultor de 20 anos de idade)

Desde pequena sempre gostava de horta, das flores... quando estavam bonitas as coisas. Sempre me interessei. [...] Antigamente tínhamos enxada, arado e hoje temos máquinas. É mais fácil! É um trabalho duro e pouco valorizado. (Agricultora de 67 anos de idade) 
Gosto da parte de plantar e tirar teu sustento da terra. Ver as coisas crescer e dar fruto. [...] É um trabalho muito difícil. Dependemos muito do clima. Se não ajuda ficamos muito tempo sem poder colher. A tecnologia ajudou, ficou mais fácil de trabalhar. [...] Trabalhamos com estufas. É mais fácil. Não precisa ir na chuva. [...] Um problema são as mercadorias que vem de fora, não conseguimos competir com o preço deles. (Agricultor de 20 anos de idade)

Neste contexto, as falas dos agricultores nos reportam ao prazer de estar em contato com a natureza, cujo ambiente é tranquilo e agradável, e participar do processo de desenvolvimento dos produtos naturais são fatores de satisfação no trabalho agrícola. Nos estudos de Vedana (2015) com agricultores familiares no momento da venda de seus produtos na Central de Abastecimento do Estado do Rio Grande do Sul (CEASA/RS), localizada na capital Porto Alegre, comentam da satisfação de trabalhar na lavoura e até mesmo de caminhar sobre o solo da propriedade rural. É importante salientar que a CEASA/RS é o local onde a maioria dos agricultores do município de Linha Nova vendem seus produtos. Ainda pela pesquisa desta autora, percebe-se a venda dos produtos e a desvalorização dos produtos agrícolas também são apontados como características negativas do trabalho.

É interessante observar que alguns entrevistados que expressaram os pontos positivos da agricultura são jovens, filhos de agricultores que permanecem trabalhando no setor junto a família. Estes ainda comentam da escassez de ferramentas para o trabalho, das variações climáticas que influenciam na produção e da dificuldade de manter os preços dos produtos da região que acabam sendo influenciados pelo comércio dos produtos de outros estados na CEASA/RS.

\section{O significado do trabalho, qualidade de vida e migração dos jovens.}

Ao iniciar a reflexão sobre o significado do trabalho e a migração dos jovens que atuam na agricultura familiar para outras atividades nas cidades maiores, há que se trazer em evidência a relação da quantidade de jovens. Contabilizaram-se 63 filhos entre as 29 famílias que geraram herdeiros. Desse número, 11 são crianças menores de quinze anos de idade. Conforme Conjuve (2006), a juventude se delimita entre o período de 15 a 29 anos de idade. Portanto, dos demais 52 filhos maiores de quinze anos, somente 18 permanecem trabalhando na agricultura familiar. Destes, 15 são do sexo masculino e apenas 3 do sexo feminino. A partir desse resultado e possível inferir que ocorre a migração de parcela significativa de jovens em busca de outros empregos nas cidades 
maiores e ainda, que a migração é maior em jovens do sexo feminino, achado este que encontra respaldo na literatura.

Em seus estudos, Gaviria e Pezzi (2007) observam que, em geral, moças e rapazes pretendem atuar fora da agricultura, manifestando interesse em cursos de nível médio ou superior. Brumer (2004) acredita que a migração de ambos os sexos também esteja sendo influenciada pelos meios de comunicação e transporte, trazendo mais informações e maior contato com o meio urbano. A autora observa que estas mudanças parecem ter mais efeito sobre as moças por terem, em média, níveis de escolaridade mais elevados que dos rapazes.

Seguindo com a compreensão a respeito desses indicadores de migração resultantes dessa pesquisa, torna-se relevante trazer a luz conceitos de qualidade de vida no trabalho, o que tende a ser um dos fatores intervenientes na migração dos jovens. $O$ trabalho na agricultura familiar se caracteriza como um trabalho autônomo, onde os próprios membros de uma família lideram e desenvolvem o negócio. Neste contexto, essa atividade contempla a maioria dos fatores apresentados no modelo de QVT de Walton (1973). Conforme as respostas dos entrevistados, as dimensões de maior destaque pelo modelo de QVT de Walton (1973) são a autonomia, significado da tarefa, identidade da tarefa, variedade de habilidades, liberdade de expressão e responsabilidade social pelos produtos/serviços. De acordo com o modelo de Hackman e Oldham (1976), a variedade das tarefas, a identidade do trabalho e o significado do trabalho são características que contribuem para dar sentido ao trabalho.

Como ponto positivo é mencionado também a satisfação de trabalhar próximo à natureza e ao ar livre. Trabalhar num ambiente agradável, tão belo e calmo quanto junto à natureza, ouvindo o cantar dos pássaros e sentindo o agradável aroma da terra e das flores. Soa poético, mas é a realidade de quem trabalha na agricultura de pequeno porte e que se contrapõe totalmente ao ambiente industrial. Considerando estes aspectos, Morin (2001) destaca a importância do prazer e do sentimento de realização no desenvolvimento das tarefas para que o trabalho tenha sentido, e complementa que tanto o processo quanto o fruto do trabalho auxiliam o sujeito a descobrir e formar sua identidade. 
Contudo, também há alguns aspectos negativos do trabalho junto à natureza. Conforme Adissi (2011), por ser um local de trabalho ao ar livre, o trabalhador também fica exposto a situações de risco como, a insolação, as chuvas e ventos e a presença de animais peçonhentos, além das topografias e condições do solo que demandam cargas de trabalho de diferentes intensidades. Muitas destas características foram evidenciadas pelos entrevistados (pais) como fator negativo para os que já atuam nesse setor, no entanto, alguns destacaram ser um dos motivos da não permanência dos jovens na agricultura.

A partir do número reduzido de jovens, filhos de agricultores, que permanecem atuando no empreendimento da família, e considerando a expressão verbal de alguns pais, pode-se inferir que a migração é um indicador de que os jovens não querem mais atuar em atividades pesadas, sendo que isso foi expresso da seguinte forma pelos pais: “eles não querem trabalho judiado [...] é difícil. Nós aguentamos, mas eles não querem (agricultora de 63 anos, mãe de dois filhos). Monteiro (2004) comenta que, de fato, as gerações mais novas tendem a perceber o trabalho agrícola como sofrido e desgastante. Iida (2005) classifica o trabalho na agricultura entre os mais árduos que se conhece e, além disso, o trabalho é executado com adoção de posturas inconvenientes, exercido com grande aplicação de força muscular e em ambientes climáticos desfavoráveis. Conforme Gaviria e Pezzi (2007), os próprios pais dos jovens não desejam que os filhos sejam agricultores, frisando as dificuldades, o desgaste físico e o sofrimento causado pelo trabalho nesse setor, salientando ainda a escassez dos recursos, como máquinas, terra e capital para novos investimentos.

De acordo com as pesquisas de Brumer (2004) há vários fatores que interferem na percepção dos jovens sobre o trabalho agrícola.

A seletividade da migração por idade e sexo pode ser explicada, em grande parte, pela falta de oportunidades existentes no meio rural para a inserção dos jovens, de forma independente da tutela dos pais; pela forma como ocorre a divisão do trabalho no interior dos estabelecimentos agropecuários e pela relativa invisibilidade do trabalho executado por crianças, jovens e mulheres; pelas tradições culturais que priorizam os homens às mulheres na execução dos trabalhos agropecuários mais especializados, tecnificados e mecanizados, na chefia do estabelecimento e na comercialização dos produtos; pelas oportunidades de trabalho parcial ou de empregos fora da agricultura para a população residente no meio rural; e pela exclusão das mulheres na herança da terra. (Brumer, 2004: 210) 
Ter a própria renda também foi apontado por alguns pais como fator que influenciou na decisão dos filhos: "Pois é muito ruim o trabalho na roça. Assim eles ganham o salário deles." (Agricultora de 49 anos de idade, mãe de três filhos). Gaviria e Pezzi (2007: 45) acreditam que "a vontade de adquirir renda autônoma geralmente está associada à migração para espaços produtivos fora da agricultura, pois os ganhos são maiores do que os obtidos em ocupações agrícolas". Além disso, segundo as autoras, a renda lhes dá certa liberdade do domínio exercido pelos pais, ou seja, a independência. Brumer (2004) esclarece que os jovens que trabalham na agricultura familiar, têm suas necessidades básicas atendidas pelos membros da família, mas quando pretendem comprar algo ou ter uma atividade de lazer fora do lar, devem pedir dinheiro aos pais.

Outras influências para a busca de outros empregos pelos jovens foram: o desenvolvimento dos meios de comunicação e de transporte, encurtando as distâncias entre o ambiente rural e urbano (Brumer, 2004); e o avanço de indústrias e outros setores industriais para os distritos rurais (Buainain et al., 2003), trazendo o emprego, antes disponível apenas nas grandes metrópoles, mais perto do agricultor. Estas facilidades aliadas com as oportunidades de estudos são portas de acesso para a escolha de outras profissões.

Há fortes indícios de que os fatores expostos até o momento são relevantes e/ou determinantes para o reduzido número de moças que permanecem no empreendimento agrícola da família. Mesquita e Mendes (2012) destacam como outro fator para a emigração feminina a desvalorização do seu trabalho na agricultura, considerado como "ajuda" mesmo que o tempo dedicado ao trabalho seja equivalente a do homem. As autoras salientam que, diferente dos homens que se dedicam inteiramente ao trabalho agrícola, muitas vezes a carga horária do trabalho feminino acaba sendo superior à deles, pois além das atividades agrícolas precisam conciliar com os afazeres domésticos e trato de animais.

Refletindo sobre a importância que a mulher exerce na agricultura familiar, Mesquita e Mendes (2012: 15) argumentam que "as mulheres agricultoras não são apenas as principais responsáveis pelas atividades de manutenção do núcleo familiar, mas desempenham um papel fundamental no trabalho relacionado a lavouras e a criação de animais". As autoras ressaltam sua importância na dinâmica da unidade de produção, interferindo na esfera produtiva e reprodutiva. 
Neste contexto, destaca-se ainda a redução drástica da taxa de fecundidade rural. Brumer (2004) comenta que 1970 a média de filhos por mulher era de 5,62 e foi reduzindo gradativamente ano após ano, chegando à média de 2,62 em 1995. Nesta pesquisa observa-se que a taxa de fecundidade vem reduzindo ainda mais. Estes resultados oferecem uma prévia do rumo da agricultura familiar, que se mostra preocupante. Brumer (2004: 210), analisando as informações disponíveis sobre a população rural do Rio Grande do Sul, aponta dois problemas:

a) o aumento do número de homens celibatários no meio rural, com consequências sobre o desenvolvimento de atividades produtivas agrícolas, tendo em vista o importante papel desempenhado pelas mulheres como mão de obra familiar não remunerada; b) a defasagem entre o número de moças e o de rapazes, o que pode 'forçar' um número maior de rapazes a emigrar, tendo em vista que raramente os jovens rurais encontram parceiras originárias do meio urbano que se disponham a viver no meio rural.

A agricultura familiar carece de avanços tecnológicos e políticas governamentais que visem melhorar o trabalho nesse setor, a fim de torná-lo mais adequado para ser desempenhado não somente pelo sexo feminino, mas a todos os trabalhadores.

\section{Considerações finais}

Esta pesquisa permitiu compreender o significado do trabalho para os trabalhadores da agricultura familiar e aspectos que interferem no desinteresse da maioria dos jovens, filhos de agricultores, pelo trabalho agrícola. Apesar do trabalho normalmente ser considerado árduo, pesado, envolvendo bastante esforço físico e exposição aos fenômenos naturais, esta pesquisa mostrou que a maioria dos agricultores tem uma visão positiva do seu trabalho, principalmente com relação à liberdade, autonomia e o sentimento de bem-estar junto à natureza.

Esta visão da agricultura familiar difere quando se pretende justificar a não permanência dos filhos dos agricultores no empreendimento da família, os quais fazem menção principalmente aos aspectos negativos do trabalho. Compreende-se que a falta de avanços tecnológicos na agricultura de pequeno porte, a expansão das indústrias para o ambiente rural e os melhores acessos à educação e transporte, permitiram novas oportunidades para estes jovens, garantindo renda e tornando-os mais independentes. 
No entanto, o índice de jovens mulheres que permanecem na agricultura, associado à baixa taxa de fecundidade, torna preocupante o futuro da agricultura familiar na região sul do Brasil. Caso não forem tomadas medidas administrativas, tecnológicas e/ou políticas mais eficientes para este setor, os alimentos produzidos na agricultura familiar poderão ficar escassos e com preços elevados.

Por fim, sugere-se que para seguir e complementar essa pesquisa, seja realizada uma investigação mais aprofundada com os filhos de agricultores com relação aos motivos que os levaram a não permanecer trabalhando no empreendimento agrícola da família.

\section{Referências}

ABERGO. Associação Brasileira de Ergonomia. $O$ que é Ergonomia. Disponível em: <http://www.abergo.org.br/> Acesso em 02 abr. 2014.

ADISSI, Paulo José. Ergonomia no trabalho agrícola. In: MÁSCULO, Francisco Soares; VIDAL, Mário César (Org.). Ergonomia: trabalho adequado e eficiente. Rio de Janeiro, RJ: Elsevier, p. 490-502, 2011.

BUAINAIN, A. M.; ROMEIRO, A. R; GUANZIROLI, C. Agricultura Familiar e o novo mundo rural. Sociologias, Porto Alegre, ano 5, $\mathrm{n}^{\circ}$ 10, jul/dez, p. 312-347, 2003.

BRASIL. Ministério do Desenvolvimento Agrário. Publicação Especial do Ministério do Desenvolvimento Agrário. Plano Safra da Agricultura Familiar 2012/2013. jun. 2012. Disponível em: <http://portal.mda.gov.br/plano-safra/arquivos/view/Cartilha_Plano_Safra.pdf>. Acesso em: 23 out. 2014.

BRUMER, Anita. Gênero e Agricultura: a situação da mulher na agricultura do Rio Grande do Sul. Estudos Feministas, Florianópolis, v. 12, n.1, jan./abr, p. 205-227, 2004.

CAMARANO, Ana Amélia e ABRAMOVAY, Ricardo. Exodo rural, envelhecimento e masculinização no Brasil: Panorama dos últimos 50 anos. IPEA, n. 621, 1999.

CODO, W. Um diagnóstico do trabalho: em busca do prazer. In: TAMAYO, A.; BORGESANDRADE, J.; CODO, W. (Eds.) Trabalho, organizações e cultura. São Paulo, SP: Cooperativa de Autores Associados, p. 21-40, 1997.

CONJUVE. Política Nacional de Juventude: diretrizes e perspectivas. São Paulo: Conselho Nacional de Juventude: Fundação Friedrich Ebert, 2006.

DUL, Jan; WEERDMEESTER, B. A. Ergonomia prática. 3. ed., rev. e ampl. São Paulo, SP: Edgard Blücher, p.163, 2012.

ECKERT, Cornélia; ROCHA, Ana Luiza Carvalho da. Etnografia: saberes e práticas. Revista Iluminuras. V.9, n.21, 2008.

GAVIRIA, Margarita Rosa; PEZZI, Silvane Maria. O poder simbólico da renda na mobilização social de jovens de comunidades rurais. In: MENASCHE, Renata (Org.). A agricultura familiar à mesa: saberes e práticas da alimentação no Vale do Taquari. 1. ed. Porto Alegre, RS: UFRGS, p. 198, 2007.

GOMES FILHO, João. Ergonomia do objeto: sistema técnico de leitura ergonômica. 2 ed. São Paulo, SP: Escrituras, p. 267, 2010.

HACKMAN, J. R., OLDHAM, G. R. Motivation through the design of work: test of a theory. Organizational Behavior and Human Performance, v. 16, p. 250-279, 1976.

IBGE. Censo Agropecuário 2006. Rio de Janeiro, 2006. 777 p. Disponível em: http://biblioteca.ibge.gov.br/d_detalhes.php?id=751. Acesso em: 12/03/2014. 
IIDA, Itiro. Ergonomia: projeto e produção. 2. ed., rev. e ampl. São Paulo, SP: Edgard Blücher, p. 614, 2005.

KROEMER, K. H. E.; GRANDJEAN, Etienne. Manual de ergonomia: adaptando o trabalho ao homem. 5. ed. Porto Alegre, RS: Bookman, p. 327, 2005.

LIMA, J. C.; HOLZMANN, L. Tempo, espaço e trabalho. In: ECKERT, C.; ROCHA, A. L. C. (Org.) Etnografias do trabalho, narrativas do tempo. Porto Alegre: Marcavisual, 2015. P. 52-77.

MARCONDES, Nilsen Aparecida Vieira; BRISOLA, Elisa Maria Andrade. Análise por triangulação de métodos: um referencial para pesquisas qualitativas. Revista Univap, v. 20, n. 35, jul. 2014.

MARX, K. Os manuscritos econômicos e filosóficos. Lisboa, Portugal: Edições 70, v. 22, 1993.

MATOS, Eliane; PIRES, Denise. Teorias administrativas e organização do trabalho: de taylor aos dias atuais, influências no setor saúde e na enfermagem. Texto Contexto Enferm, Florianópolis, 2006 Jul-Set; 15(3): 508-14.

MENDONÇA, J. R. C.; BARBOSA, M. L. A; DURÃO, A. F. Fotografias Como um Recurso de Pesquisa em Marketing: o Uso de Métodos Visuais no Estudo de Organizaçőes de Serviços. RAC, v. 11, n. 3, Jul./Set. 2007: 57-81

MESQUITA, Lívia Aparecida Pires de; MENDES, Estevane de Paula Pontes. Agricultura familiar e estratégias: a participação feminina na reprodução socioeconômica e cultural. Espaço em Revista, Universidade Federal de Goiás, GO, vol. 14, n. 1, jan./jun, p. 14-23 2012.

MONTEIRO, Janne Cavalcante. O processo de trabalho e o desencadeamento dos agravos à saúde dos trabalhadores rurais: um estudo ergonômico na agricultura familiar em Santa Catarina. 2004. 182 f. Tese (Doutorado em Eng. de Produção e Sistemas). Universidade Federal de Santa Catarina, Florianópolis, 2004.

MORAES, Anamaria de; MONT'ALVÃO, Cláudia. Ergonomia: conceitos e aplicações. 4. ed., rev. atual. e ampl. Teresópolis, RJ: 2AB, p. 223, 2010.

MORIN, E. M. L'efficacité organisationnelle et le sens du travail. In: PAUCHANT, T. C. et coll. (Coord.). La quête du sens: gérer nos organisations pour la santé des personnes, de nos sociétés et de la nature. Québec: Éditions de l'organisation, p. 257-286,1996.

MORIN, Estele M. Os sentidos do trabalho. Revista de Administração de Empresas, São Paulo, v. 41, n. 3, jul./set, p. 8-19, 2001.

PESSOA, Y. S. R. Q.; ALCHIERI, J. C. Qualidade de Vida em Agricultores Orgânicos Familiares no Interior Paraibano. Psicologia: ciência e profissão, 2014, 34 (2), 330-343

PRODANOV, Cleber Cristiano; FREITAS, Ernani Cesar de. Metodologia do trabalho científico: métodos e técnicas da pesquisa e do trabalho acadêmico. 2. ed. Novo Hamburgo, RS: Feevale, p. 276, 2013.

RENNER, J. S. Diagnóstico diferencial dos Distúrbios Osteomusculares Relacionados ao Trabalho. Boletim da Saúde, Porto Alegre, RS, v. 19, n. 1, jan./jun. 2005.

RIBAS, J. M. B. Trabalhar em la modernidade industrial. In: RIBAS, J. M. B.; TOMÁS, M. J. E.; DURÁN, C. G.; ARTILES, A. M. Teoría de las relaciones laborales: fundamentos. Barcelona: UOC, p. 165, 2003.

ROCHA, A. L. C.; ECKERT, C. Um projeto antropológico: o estudo da memória do trabalho na cidade moderno-contemporânea. In: ECKERT, C.; ROCHA, A. L. C. (Org.) Etnografias do trabalho, narrativas do tempo. Porto Alegre: Marcavisual, p. 16-51, 2015.

SCHUCH, Claudio. Qualidade de vida no trabalho: a percepção dos professores da universidade do planalto catarinense. 2001. 93 f. Dissertação (Mestrado em Administração). Universidade Federal de Santa Catarina, Florianópolis, 2001.

SCHWARTZMAN, S.; COSSIO, M.B. Juventude, educação e emprego no Brasil. Cadernos Adenauer VII. Jun. 2015, 14 p. Disponível em: < http://www.researchgate.net/publication/224771453_Juventude_educao_e_emprego_no_Brasil> . Acesso em: 07 ago 2015.

SOUZA, Dilmara Veríssimo de; ZIONI, Fabiola. Novas perspectivas de análise em investigações sobre meio ambiente: a teoria das representações sociais e a técnica qualitativa da triangulação de dados. Saúde e Sociedade, v.12, n.2, p.76-85, jul-dez 2003. 
TOLFO, Suzana da Rosa; PICCININI, Valmíria. Sentidos e significados do trabalho: explorando conceitos, variáveis e estudos empíricos brasileiros. Psicologia \& Sociedade, 19 (ed. esp.), 1: 38-46, 2007.

VEDANA, V. Práticas e representações sobre o trabalho no comércio de alimentos na CEASA/RS. In: ECKERT, C.; ROCHA, A. L. C. (Org.) Etnografias do trabalho, narrativas do tempo. Porto Alegre: Marcavisual, p. 78-99, 2015.

VÍCTORA, C.G.; KNAUTH, D. R.; HASSEN, M. Pesquisa qualitativa em saúde: uma introdução ao tema. Porto Alegre: Tomo, 2000.

WALTON, R. E. Qualidade de Vida no Trabalho: o que é? Sloan Management Review.

Cambridge, v. 15, n. 1, p. 11-21, dez. 1973.

WILKINSON, John. Distintos enfoques e debates sobre a produção familiar no meio rural. Agroecologia e Desenvolvimento Rural Sustentável. Porto Alegre, RS, v.1, n.3, jul./set. 2000.

Recebido em: 31/10/2015.

Aprovado em: 06/04/2016. 